\title{
LA INDUSTRIA Y EL ESPACIO RURAL
}

\author{
Eugenio A. CLIMENT LOPEZ \\ Dpto. de Geografía y Ordenación del Territorio \\ Universidad de Zaragoza
}

\begin{abstract}
Resumen: Desde la década de los setenta se ha dado una profunda reestructuración de la industria, lo cual ha producido cambios en las pautas de localización industrial, como consecuencia de los cuales el espacio rural ha experimentado un proceso de industrialización destacable, aunque de alcance limitado.
\end{abstract}

Palabras clave: Reestructuración industrial, espacio rural.

\begin{abstract}
Since the seventies a restructuration of the industry has taken place, generating changes in the industrial location; therefore rural space has undergone a remarkable but limited industrialisation process.
\end{abstract}

Key words: Restructuration of the industry, rural space.

A lo largo de las dos últimas décadas hemos asistido, en España y en los países de nuestro entorno, a un desarrollo de la industria en el espacio rural que, sin ser espectacular, contrasta muy claramente con la masiva pérdida de empleos de las aglomeraciones urbano-industriales.

Podría decirse que el campo ha recuperado una antigua función después de un largo paréntesis, pues, como es sabido, antes de la revolución industrial la mayor parte de las actividades manufactureras se localizaban en el campo, donde residía la mayor parte también de la población. La disponibilidad de ciertas materias primas, la energía de las corrientes fluviales o del carbón vegetal y la posibilidad de contar con una mano de obra abundante, aprovechando los tiempos muertos de la actividad agraria, son los factores que explican la localización de la industria en el mundo rural, acomodándose a una distribución en el espacio dispersa y a una organización laxa de las actividades productivas, destacándose de forma señalada el sistema de trabajo a domicilio. 
La mecanización de las tareas fabriles y la producción en serie, que constituyen aspectos clave de la revolución industrial, hicieron inviable el trabajo a domicilio, favoreciendo la concentración de las actividades productivas en la fábrica, a la vez que la búsqueda de economías externas y de aglomeración potenciaba la concentración espacial de las fábricas en los núcleos urbanos. La vieja industria artesana rural fue desapareciendo paulatinamente ante la competencia de la nueva industria mecanizada, que sistemáticamente se localizaba en las ciudades, dando un fuerte impulso al proceso de urbanización. El campo perdió así una de sus funciones tradicionales, quedando relegado al papel de mero proveedor de materias primas y mano de obra.

La crisis económica iniciada en los años setenta ha vuelto a llevar la industria al espacio rural, lo que significa que se ha producido un cambio en las pautas de localización de las empresas industriales, cambio cuyas causas hay que buscar en la profunda reestructuración de la actividad manufacturera operada como respuesta a la crisis. El objeto de este artículo es, en la medida en que su brevedad lo permita, señalar los aspectos de esa reestructuración industrial que mejor contribuyen a explicar las pautas de localización que han favorecido el reciente desarrollo de la industria en el campo.

\section{LA REESTRUCTURACION DE LAS ACTIVIDADES INDUSTRIALES}

A principios de los años setenta la dislocación del sistema monetario internacional y el fuerte encarecimiento de energía y materias primas trajeron consigo un endurecimiento notable de la competencia en los mercados internacionales; una de sus consecuencias inmediatas fue la inviabilidad del enorme aparato productivo industrial creado tras varias décadas de desarrollo continuado, lo que obligó a su reestructuración. El aspecto más visible de la misma fue la drásticạ reducción de capacidad productiva operada en los sectores de demanda débil (metalurgia básica, construcción naval, textil, calzado, madera y productos minerales no metálicos), proceso encauzado en España a través de los planes de reconversión industrial de los años ochenta, acompañada del crecimiento de los de demanda fuerte (material y maquinaria eléctrica y electrónica, aeronáutica, química e instrumentos de precisión).

Además de esa reestructuración sectorial, las empresas industriales tuvieron que adoptar estrategias encaminadas a la reducción de costes productivos, centrándose sobre todo en el ahorro energético, en el uso más eficiente de las materias primas y en la reducción de los costes laborales, siendo la tecnología el instrumento idóneo para ello, pues permite crear nuevos productos, desarrollar procesos de producción más baratos y eliminar mano de obra. Todo ello ha repercutido en la organización 
industrial, cuestionando seriamente la eficacia del sistema basado en los grandes complejos industriales integrados y en las grandes fábricas, que ha demostrado, en general, una notable falta de elasticidad a la hora de responder a la intensificación de la competencia, a la aceleración del cambio tecnológico y a la necesidad de controlar los costes laborales.

En su lugar se ha ido imponiendo un nuevo sistema de organización al que se denomina modelo de especialización flexible (Costa, 1990; Storper y Harrison, 1992), que se basa en la fragmentación de los procesos productivos: hay una alternativa a la gran fábrica y es una red de pequeñas y medianas empresas (PYMEs) especializadas en tareas muy concretas, pequeños segmentos del proceso productivo global, relacionadas entre sí de una forma flexible y apoyadas por PYMEs especializadas en servicios a la producción. Estas redes de PYMEs pueden competir con los grandes establecimientos industriales, a pesar de que las economías de escala juegan a favor de éstos, gracias al cambio tecnológico: muchas de las nuevas máquinas, cada vez más eficaces y autónomas, no requieren estar concentradas en grandes fábricas y permiten automatizar la producción de series cada vez menores, pudiendo así atender demandas muy atomizadas e incluso trabajar a medida o por encargo a precios muy competitivos. Es lo que se llama tecnología flexible, que ha privado a la producción masiva en grandes series de una parte notable de sus ventajas. Tanto es así que las grandes empresas han adoptado el modelo, aplicando la descentralización productiva, que consiste en segmentar los procesos de producción antes integrados, asignando cada segmento a un establecimiento propio o, muy frecuentemente, subcontratando su realización con diferentes PYMEs, sin perder el control global del proceso.

Este modelo requiere también un mercado de trabajo flexible, a cuya consecución han ido encaminadas la revisión de las formas de contratación (con el notable incremento de las de duración temporal), la progresiva desregulación de las relaciones laborales y, al margen ya de la legalidad, la extensión de la economía sumergida y la "recuperación" del trabajo a domicilio.

\section{NUEVAS PAUTAS DE LOCALIZACION INDUSTRIAL}

La reestructuración sectorial antes señalada, por una parte, ha convertido en áreas en declive industrial a las regiones y comarcas especializadas en los sectores de demanda débil, cuya reconversión o reducción de capacidad productiva no ha ido acompañada, al menos al mismo ritmo, de la reindustrialización o instalación de nuevas empresas de otros sectores. Por otra parte, ha revitalizado el tejido industrial de las grandes áreas metropolitanas con la instalación de empresas de los sectores de demanda fuerte, que buscan en ellas lo que no pueden encontrar en otros lugares: 
personal altamente cualificado, centros de investigación y acceso fácil a la información.

El modelo de especialización flexible tiene también sus consecuencias espaciales. En primer lugar, la descentralización puesta en marcha por las grandes empresas ha traído consigo en una buena parte de los casos la relocalización de todos o algunos de los segmentos resultantes del proceso; en general, las tareas de dirección, innovación, investigación y comercialización se mantienen en las áreas urbanas de origen, donde es más fácil encontrar personal cualificado, flujos de información y empresas de servicios a la producción. Por el contrario, los trabajos más repetitivos y los que requieren abundante mano de obra poco cualificada se trasladan a lugares donde ésta resulta barata y poco conflictiva, aunque estén muy alejados de los centros de dirección; las tecnologías de la información, singularmente la informática y las telecomunicaciones, permiten programar, coordinar y controlar desde un punto concreto los procesos de fabricación de varios establecimientos industriales distantes entre sí y de aquél. Este proceso constituye una de las bases de la proliferación reciente de establecimientos y empleos industriales en algunos países del Tercer Mundo, en algunas regiones atrasadas de los países industrializados y en algunas áreas del espacio rural (Méndez, 1988).

Pero no todo el desarrollo industrial de estos espacios periféricos se debe a la descentralización productiva. El sistema basado en la especialización flexible se ha ido configurando también desde abajo, mediante la creación progresiva de PYMEs centradas en pequeños segmentos de la producción que se complementan mutuamente; las relaciones de competencia y de cooperación que mantienen entre sí acaba tejiendo una densa red de empresas. Cuando este fenómeno se produce en un territorio concreto sin industria previa se habla de industrialización endógena o desarrollo endógeno (Garofoli, 1992). Dos condiciones, al menos, han de darse en un territorio para que tenga lugar un proceso de este tipo: la primera es la abundancia de pequeñas empresas, agrícolas y comerciales, y de trabajadores autónomos, lo cual implica capacidad de iniciativa, experiencia de gestión y acumulación inicial de capital, sin las cuales no podría darse la creación de empresas industriales. La segunda es la existencia de una mano de obra abundante, poco conflictiva y dispuesta a mantener unas relaciones laborales flexibles (en régimen de contratación temporal, a tiempo parcial o jornada reducida e incluso a domicilio; en ocasiones con contrato, en ocasiones de manera "informal" o "sumergida", eufemismos habitualmente utilizados para no hablar de ilegalidad o fraude).

El proceso de industrialización endógena mejor estudiado es, probablemente, el de la Italia del nordeste y centro o "tercera Italia" (Fua, 1988), que es el que ha servido de base para la formalización del modelo. Al identificarse procesos similares en otros países los economistas recordaron los trabajos de Alfred Marshall, difundidos 
a finales del siglo pasado, en los que se utilizaba el término distrito industrial para referirse a ciertos territorios en que se desarrollan procesos de industrialización endógena a base de redes de pequeñas y medianas empresas (Becattini, 1992; Trullen, 1990). Los distritos industriales han experimentado en los años setenta y ochenta un desarrollo de la industria superior al de las regiones de antigua industrialización, demostrando una elevada competitividad incluso en los aspectos en que aparentemente más ventajas podían tener las grandes empresas: la innovación tecnológica y la penetración en los mercados internacionales.

Pero en las áreas y aglomeraciones urbanas industrializadas antes de que comenzara la crisis, la reestructuración productiva ha tomado también la dirección del modelo de especialización flexible, habiéndose observado el desarrollo de redes de PYMEs, muchas de las cuales trabajan para las grandes empresas en régimen de subcontratación (Scott, 1992; Mayoral y Montero, 1992). En estas áreas abundan los pequeños empresarios y trabajadores autónomos capaces de crear dichas empresas y el mercado de trabajo se ha ido flexibilizando paulatinamente, aunque los costes laborales, en general, siguen siendo más altos que en las zonas de industrialización reciente. Las economías externas y de aglomeración que las empresas pueden obtener en las ciudades siguen siendo enormemente atractivas y la proximidad física muchas veces es insustituible, a pesar del progreso de las telecomunicaciones: piénsese, por ejemplo, que a una gran empresa no le cuesta mucho dirigir a distancia una sucursal o filial, pero que no puede hacer lo mismo con una red de PYMEs autónomas, sobre todo si aplica sistemas organizativos que requieren una gran coordinación, como por ejemplo el "just in time".

Esto hace que el término distrito industrial se aplique también a menudo a las zonas metropolitanas en que se ha detectado la existencia de importantes redes de PYMEs, aunque no parece que sea éste un uso adecuado del término.

\section{EL ESPACIO RURAL Y LAS NUEVAS PAUTAS DE LOCALIZACION INDUSTRIAL.}

La industrialización experimentada por el mundo rural a partir de los años setenta ha tenido su origen tanto en procesos de desarrollo endógeno como de descentralización productiva (Molinero, 1990). 
Algunas áreas rurales, no todas, reúnen las condiciones necesarias para una industrialización endógena ${ }^{1}$ : en primer lugar, el agricultor medio es cada vez más un empresario que dirige su explotación con vistas al mercado, en busca de la obtención de beneficios y abierto a la innovación. A diferencia de lo que ocurría hace décadas, su espíritu y capacidad resisten la comparación con los de los pequeños empresarios y trabajadores autónomos de los otros sectores económicos. Cuenta, además, con un patrimonio y una capacidad de ahorro que, aunque modestos, pueden ser movilizados para la creación de empresas industriales.

En segundo lugar, hay mano de obra disponible: la actividad agraria ha ido reduciendo continuamente sus efectivos, mientras que la crisis económica ha frenado la posibilidad de emigración a las ciudades, por lo que los agricultores aspiran a compatibilizar su trabajo en la agricultura con otro, si lo hubiera, y los jóvenes que no pueden ni quieren marcharse demandan nuevos puestos de trabajo. Esta mano de obra se adapta bien a las condiciones de un trabajo flexible (de temporada, a tiempo parcial, a domicilio) y resulta poco conflictiva, tanto por la falta de tradición sindical como por la seguridad relativa que ofrece la explotación agraria familiar.

El espacio rural, por otra parte, puede ser incluido en el grupo de los llamados espacios periféricos $y$, como tal, se ha beneficiado de la relocalización de establecimientos industriales que ha acompañado a la descentralización productiva, habiendo recibido inversiones de origen exógeno o que, en todo caso, responden a un estímulo directo de carácter exógeno, atraídas fundamentalmente por las condiciones del mercado de trabajo anteriormente descritas. Juega un papel importante en este caso la accesibilidad respecto a las áreas de antigua industrialización, normalmente ciudades, de donde proceden las inversiones y los estímulos.

Pero, aunque el campo se haya beneficiado de las nuevas pautas de localización industrial, recuperando así una función perdida hace mucho, no caben valoraciones entusiastas de la industrialización reciente del mundo rural. Téngase en cuenta que en las áreas y aglomeraciones urbanas tienen su emplazamiento exclusivo las empresas de los sectores de demanda fuerte, así como los centros de dirección, innovación y comercialización de las grandes empresas que han entrado en la dinámica de la descentralización; además, el tejido industrial urbano se ha reestructurado en profundidad, con la creación de densas redes de PYMEs, recuperando una buena parte de la competitividad que había perdido en los primeros años de la crisis.

\footnotetext{
${ }^{1}$ Una buena colección de ejemplos españoles puede encontrarse en dos publicaciones del Instituto del Territorio y Urbanismo (1987) y en las actas de dos de las reuniones del Grupo de Geografía Industrial de la Asociación de Geógrafos Españoles (Rodríguez y Villarino, 1988; Caravaca y Jordá, 1990).
} 
Los distritos industriales, por su parte, son territorios densamente poblados que cuentan con una red apretada de ciudades pequeñas y medianas, armónicamente imbricadas con su espacio rural: la ciudad no explota el campo ni desarticula su sistema productivo, sino que una y otro aúnan esfuerzos para alcanzar un desarrollo equilibrado, paso a paso y sin rupturas; pero las ciudades son esenciales en la vertebración territorial del distrito y en el sostenimiento del proceso industrializador en tanto que centros de servicios a las empresas, nudos de la red de transportes y puntos de recepción y difusión de la información. El hecho de que algunas áreas rurales hayan puesto en marcha una industrialización de carácter endógeno merece una valoración altamente positiva, pero no se puede ignorar la fragilidad de la misma en ausencia de una densa red urbana; un área rural con industria endógena no es por sí misma un distrito industrial.

El campo ha servido en estos años frecuentemente como refugio a los sectores de demanda débil: una buena parte de las empresas creadas durante los últimos veinte años en las áreas rurales corresponde al textil y confección, el calzado, la madera y mueble y los productos minerales no metálicos o materiales de construcción. Cuando dicha creación se debe a la descentralización productiva se pone de manifiesto el deseo de mejorar la competitividad trasladando la producción a zonas con menores costes laborales. Cuando responde a una iniciativa endógena traduce las limitaciones del empresariado rural, que no tiene conocimientos suficientes, en general, para iniciar actividades de tecnología elevada, por lo que se centra en las de tecnología simple, que son las mejor conocidas y las más fáciles de desarrollar en el marco de una pequeña empresa financiada con el limitado ahorro familiar. Estas limitaciones conducen casi inevitablemente a los sectores de demanda débil, pero dado que éstos no van a tener un futuro expansivo y que sus empresas se desenvuelven en un mercado cada vez más abierto a la competencia, parece lógico concluir que la continuidad del proceso de industrialización rural no está en absoluto garantizada.

Se salva de esta valoración pesimista el sector agroalimentario, que pertenece al grupo de los de demanda intermedia y que, además, es un excelente instrumento de desarrollo equilibrado: su localización en el campo permite trabajar coordinadamente al agricultor y al industrial, que pueden ser la misma persona, en algunos aspectos, como la elección y obtención de productos, el establecimiento de estrategias de comercialización, incluyendo la promoción de denominaciones o marcas de origen, la recepción y aplicación de innovaciones y el aprovechamiento de ayudas institucionales. 


\section{BIBLIOGRAFÍA}

BECATTINI, G. (1992): "Le district marshallien: une notion socioeconomique", En, BENKO, G. et LIPIETZ, A. (Dir.): Les régions qui gagnent, 35-55, Presses Universitaires de France, París.

CARAVACA, I. y JORDA, R., (Coord.) (1990): III Reunión de Geografia Industrial, Asociación de Geógrafos Españoles, Sevilla.

COSTA, M.T. (1990): "Los nuevos problemas de la organización industrial", En, VELARDE, J. et al. (Ed.): La industria española. 155-167, Colegio de Economistas, Madrid.

FUA, G. (1988): "Las diversas vías del desarrollo en Europa". En, ETXEZARRETA, M.: El desarrollo rural integrado, 179-205, Ministerio de Agricultura, Pesca y Alimentación, Madrid.

GAROFOLI, G. (1992): "Les systèmes de petites entreprises: un cas paradigmatique de développement endogéne", En, BENKO, G. et LIPIETZ, A. (Dir.): Les régions qui gagnent. 57-80, Presses Universitaires de France, París.

INSTITUTO DEL TERRITORIO Y URBANISMO (1987): Areas rurales españolas con capacidad de industrialización endógena, Ministerio de Obras Públicas y Urbanismo, Madrid.

INSTITUTO DEL TERRITORIO Y URBANISMO (1987): Industrialización en áreas rurales, Ministerio de Obras Públicas y Urbanismo, Madrid.

MAYORAL, J. y MONTERO, M.A. (1992): Cambio industrial, revitalización de economías urbanas y desarrollo local, Comunidad de Madrid, Madrid.

MENDEZ, R. (1988): "Los espacios industriales", En, PUYOL, R. et al.: Geografía Humana, 587701, Ed. Cátedra, Madrid.

MOLINERO, F. (1990): Los espacios rurales, Ed. Ariel, Barcelona.

RODRIGUEZ, R. y VILLARINO, M. (1988): Actas de la II reunión de geografía industrial, Asociación de Geógrafos Españoles, Santiago de Compostela.

SCOTT, A.J. (1992): "L'economie metropolitaine", En, BENKO, G. et LIPIETZ, A. (Dir.): Les régions qui gagnent. 103-120, Presses Universitaires de France. París.

STORPER, M. et HARRISON, B. (1992): "Flexibilité, hiérarchie et développement régional", En, BENKO, G. et LIPIETZ, A. (Dir.): Les régions qui gagnent, 265-291, Presses Universitaires de France, París. 
TRULLEN, J. (1990): "Caracterización de los distritos industriales", En, VELARDE, J. et al. (Ed.): La industria española, 169-193, Colegio de Economistas., Madrid. 